UDC 37

LBC 60.55.325.11

\title{
FACTORS OF TRANSFORMATION OF CIVIL AND NATIONAL IDENTITY OF STUDENTS
}

\author{
Lyudmila S. Detochenko \\ South Federal University, Rostov-on-Don, Russian Federation \\ Viktor I. Filonenko \\ South Federal University, Rostov-on-Don, Russian Federation
}

\begin{abstract}
In article on the basis of monitoring interregional sociological study "Contradictions and paradoxes of socialization of student's youth in transition conditions of modern Russian society" (comparative analysis of research results of 2006, 2011 and 2016) are considered civil and national identity of students. Dynamics of the level of civic and national identity, behavioral and emotional attitudes of the respondents are the basis for the study the need for a systematic and purposeful "identity politics". Factor analysis of the dynamics of self-identification of students (territorial specificity of policies, training, type of institution, socio-economic and political peculiarities of the region, cultural traditions) allows to identify the number of students requiring special attention from professionals working with young people. Civic identity is highlighted as a priority identity in a multicultural Russian society. Revealed a direct correlation between civic and national identity of the respondents and quality of social capital of youth, the ability to reproduce socially significant forms of activity.

Key words: civil identity, national identity, self-identity, socialization, ethnic principles, identity factors, identity politics.
\end{abstract}

УДК 37

ББК 60.55.325.11

\section{ФАКТОРЫ ТРАНСФОРМАЦИИ САМОИДЕНТИФИКАЦИИ СТУДЕНЧЕСКОЙ МОЛОДЕЖИ}

\author{
Людмила Станиславовна Деточенко \\ Южный федеральный университет, г. Ростов-на-Дону, Российская Федерация \\ Виктор Иванович Филоненко \\ Южный федеральный университет, г. Ростов-на-Дону, Российская Федерация
}


Ключевые слова: гражданская идентичность, национальная идентичность, самоидентификация, социализация, межэтнические установки, факторы идентичности, политика идентичности.

В настоящее время растет интерес к теоретическому осмыслению феномена идентичности. Увеличивается количество не только фундаментальных, но и прикладных эмпирических исследований. Актуальность проблемы давно вышла за пределы научного дискурса. Сегодня идентичность корректирует и определяет политику государств и надгосударственных структур, идеологические рамки официальных средств массовой информации, цели и формы воспитательной политики образовательных учреждений. Воспроизводство положительной идентичности, под которой мы понимаем идентичность, соответствующую ожиданиям социального окружения и влекущую за собой воспроизводство личностью социально значимых форм поведения, является необходимым условием не только консолидации общества, но и противостояния негативным глобальным вызовам современности. Основываясь на позициях конструктивизма, следует подчеркнуть особое значение формирования положительной идентичности студенчества, что обусловлено целым рядом факторов, связанных со спецификой молодежи как особой социально-демографической группы: активностью, инновационностью, склонностью к протестным формам поведения. Университеты воспитывают будущие руководящие кадры нашего государства, а значит формирование положительной идентичности у студентов - это залог преемственности, стабильного развития российского общества. Именно поэтому в качестве цели нашего исследования выступает анализ факторов и условий формирования положительной гражданской и этнической идентичности студенчества Ростовской области и других регионов России, а также выбор приоритетной формы самоидентификации в конструировании воспитательной системы высших учебных заведений.

\section{Методология исследования}

Объектом социологического исследования «Противоречия и парадоксы социализации студенческой молодежи в условиях транзитивности современного российского общества», проведенного по инициативе Центра со- циально-политических исследований ЮФУ (руководитель д.с.н., доцент В.И. Филоненко), являются социализация и воспитание современного российского студенчества (на примере вузов Ростовской области и других регионов России). Целью исследования стал комплексный анализ современного состояния социализации вузовского студенчества и рассмотрение возможностей ее оптимизации как фактора укрепления социального порядка. Полученные данные сопоставлялись с результатами социологических исследований 2006, 2011 годов. Методом исследования выступало анкетирование. Тип выборки - стратификационная. Общая выборочная совокупность составила 3900 человек. Сроки проведения исследования декабрь 2015 г. - декабрь 2016 года. Программа исследования предусматривала:

- изучение самоидентификации студентов высших учебных заведений;

- анализ факторов, влияющих на формирование различных типов идентичности студентов;

- выявление приоритетной формы самоидентификации студенчества на основе поведенческих аттитюдов при построении воспитательной системы высших учебных заведений.

В рамках исследования выдвигался ряд гипотез:

- современное российское студенчество неоднородно, причем дифференцированность по социально значимым параметрам преобладает над интегрированностью. Одним из факторов, определяющих неодноростность студенчества, является различная самоидентификация респондентов. Следовательно, дифференцированность социализирующих воздействий должна сочетаться с задачей улучшения межгрупповых и межэтнических взаимодействий внутри студенческой среды;

- существует явное расхождение между «востребованной» обществом и государством ради сохранения стабильности моделью идентичности и реальной самоидентификацией студентов, ориентированной на конформизм и индивидуальные ценности, а также 
между различными компонентами идентичности личности;

- существование института высшего образования на сегодняшнем этапе развития страны можно обозначить как парадоксальное. К снижающим качество социализации следует отнести следующие факторы: отсутствие внятной образовательной политики, а также несформулированность государственных требований к социальному типу личности выпускника вуза;

- целесообразно предположить, что эффективность процесса социализации может быть обеспечена за счет подхода развивающегося образования - обучения - воспитания. Необходимо построение интегративной модели социализации студентов, осуществляемой как целостный, всесторонний процесс, учитывающий и психосоциальное, и ролевое, и интеллектуальное, и нравственное развитие личности.

Репрезентацию полученных в рамках социологического исследования данных следует начать с определения теоретико-методологических позиций и основных категорий, используемых в исследовании.

Интерпретация полученных данных осуществляется в рамках конструктивистской парадигмы анализа социально-политических систем и изменений, основанной на трудах Б. Андерсена, П. Бурдье, Ф. Барта, Э. Геллнера, Э. Хобсбаума. Вслед за представителями конструктивизма мы предполагаем возможность сознательного, управляемого процесса формирования личностной и социальной идентичности. Основными агентами данного процесса являются семья, образовательные учреждения, СМИ. Главным же среди них является государство, чьи действия, «направленные на интеграцию национального сообщества, формирование определенного представления о “нации”, опирающегося на те или иные интерпретации “национальной” истории и культуры» [1, с. 71], получили в 1960-1970 гг. особое название - «политика идентичности».

Анализ идентичности строится на позициях единства и взаимовлияния личностной и социальной идентичности. Разграничение личной и социальной идентичности осуществляется в рамках когнитивизма Дж. Тернера, А. Тэшфела, Г. Брейкуэлл. Идентичность представляет собой когнитивный механизм регуляции поведения личности или социальных групп. В обществе она существует как на личностном, так и на социальном уровнях. Личная идентичность отрицает сходство социальных групп и базируется на биологических, интеллектуальных и нравственных категориях. Социальная идентичность не различает индивидуальных характеристик членов группы и основана на расовой, национальной, гражданской и т. д. принадлежности.

В современной науке утвердилось несколько теоретических подходов к проблеме выявления сущности и соотношения понятий гражданская и национальная идентичность. В рамках первого подхода гражданская и национальная идентичность отождествляются (Н.Л. Иванова, Г.Б. Мазилова) [7]. По мнению Д.В. Григорьева, гражданская идентичность - это свободное отожествление человека с российской нацией (народом), включенность человека в общественную, культурную жизнь страны, осознание себя россиянином, ощущение причастности к прошлому, настоящему и будущему российской нации [5]. В рамках другого подхода (Л.М. Дробижева, А.Г. Санина, А.В. Павлов), который разделяем и авторами данной статьи, подчеркивается различие гражданской и национальной идентичности.

Под гражданской идентичностью мы склонны понимать принадлежность данному государству, включающую «знания о государстве в его исторической и современной перспективе, эмоциональное отношение к государству, “идеальные” представления о гражданских нормах и ценностях, действия, в которых проявляются те или иные установки, связанные с восприятием своего места в государстве» $[12$, с. 38]. Национальная же идентичность предполагает соотнесение себя с социальной общностью и включает представления о своем народе и этносе, языке, культурных особенностях, территории, эмоциональное отношение к ним, готовность действовать во имя этих представлений [6, с. 136].

Основой любой формы идентичности является процесс идентификации, при котором индивид позиционирует себя по отношению к другим. В результате процесса идентификации происходит самоопределение по ряду при- 
знаков, выявление принадлежности к некоторому классу людей «с общими категориальными атрибутами» (антропологический тип, этническая группа, гражданство и т. д.), либо индивид оценивает свое место в социальных сетях (родственных, профессиональных, дружеских и т. д.) [3, с. 11].

В основу эмпирического исследования легло выявление самоидентификации респондентов. Анализ ответов на вопрос «Как бы Вы ответили сами себе на вопрос "Кто я такой?"》 позволяет представить структуру самоидентификации респондентов. Гражданская самоидентификация преобладает над другими видами - 59,6 \% респондентов отожествляют себя с «гражданами России». В целом для вузов Ростовской области характерно снижение уровня гражданской идентификации с $62 \%$ в 2011 г. до 60,3\% в 2016 году.

Конструирование личной идентичности происходит под воздействием социально-экономических, политических и культурных факторов. М.К. Горшков на основе многоаспектного анализа состояния динамики развития российского общества зафиксировал, что в период с 2014 по 2015 г. для российского общества в целом характерна «консолидация мировоззренчески противостоящих социальных групп», которая связана с оценкой внешних факторов как главных угроз и основных источников социально-экономического и политического кризиса РФ. Смена фокуса общественного мнения с внутренних на внешние угрозы послужила импульсом к росту патриотических настроений, возрождению исторической памяти и гражданской гордости. Особую роль здесь играет уровень идеологической открытости и готовности отвечать на запросы российской молодежи и студентов [10, с. 194]. Однако подобная тенденция сочетается со «снижением уровня доверия государственным институтам» со стороны большинства «ресурсно-благополучных групп сограждан - молодежи, материально обеспеченных, самодостаточных россиян» [2, с. 28]. В.В. Гаврилюк, отмечая наличие таких парадоксов в современной модели российской гражданственности, объясняет рост гражданской самоидентификации кризисом «либеральной» и «гибридных» моделей идентификации, показавших свою несостоятельность в условиях российского общества [2, с. 28].
В этом смысле полученные нами данные подтверждают позицию авторов. Среди факторов, детерминирующих выбор гражданской самоидентификации, можно назвать место проживания респондентов. В крупных городах (областных и краевых центрах) уровень гражданской самоидентификации ниже (54, \% респондентов, причисляющих себя к гражданам России, живут в крупных городах), в то время как для жителей малых и средних городов $(60,4 \%)$ и сельской местности $(68,5 \%)$ этот показатель выше.

Студенчество является самой активной, образованной частью российской молодежи. Владение компьютерными технологиями позволяет расширить коммуникационные и информационные возможности студентов. Склонность к сопоставлению и анализу, воспитанная в академической среде, заставляет искать глубинные причины происходящих изменений в обществе, а отсутствие действенных социальных лифтов в сочетании с высокими потребностями к самореализации повышают критический уровень оценки действительности. В условиях крупных российских городов «близость к властным институтам», широта форм участия молодых людей в гражданских и политических процессах, более острое ощущение социального и имущественного неравенства приводят к меньшему желанию респондентов причислять себя к «гражданам России». Гражданская самоидентификация характерна для 52,1 \% студентов ЮФУ (в целом), 64,2 \% РГЭУ (РИНХ), 52,9 \% ДГТУ (г. Ростов-на-Дону), 69,1 \% РостГМУ. Для «малых» городов Ростовской области этот показатель более высок (70,8 \% ДонГАУ (в целом)), 71, 1 \% ЮРГПУ (НПИ), 66,7 \% ДонГАУ (пос. Персиановский), 80,0 \% АЧИИ ДГАУ (г. Зерноград), 70,5 \% ИСОиП (филиал ДГТУ в г. Шахты). Низкий уровень гражданской самоидентификации показали студенты УРФУ (г. Екатеринбург) - 44,0 \%, что также подтверждает наше предположение. Относительно стабильная социально-экономическая ситуация Краснодарского края (даже в тяжелые «санкционные» годы он оставался «житницей» России, а финансовые вливания в туристическую сферу, сельское хозяйство (ввиду политики импортозамещения) не только не снизили, а скорее повысили благосостояние 
региона) определяет и самый высокий уровень гражданской самоидентификации студентов $(81,8 \%)$. Эмоциональная оценка факта своей гражданской принадлежности также является самой высокой именно в данном регионе 78,4 \% (КубГУ (г. Краснодар), 87,7 \% (Кубанский ГАУ (г. Краснодар)).

Еще одним фактором, влияющим на уровень гражданской самоидентификации, является уровень сохранения национальных традиций. Подобная закономерность явно прослеживается на примере респондентов Майкопа и Казани. Около 47,2 \% респондентов КалмГУ (г. Элиста), 33,3\% студентов АГУ (г. Майкоп) при ответе на вопрос «Кто я такой?» в первую очередь отметили свою национальную принадлежность. Этот показатель значительно превышает показатели респондентов из других вузов, в то время как уровень гражданской самоидентификации здесь самый низкий.

Согласно исследованию тип вуза также влияет на уровень гражданской самоидентификации. Так, 77 \% респондентов, отожествляющих себя с гражданами России, обучаются в сельскохозяйственных вузах; $61,1 \%$ - в инженерно-технических вузах и только $55,9 \%$ - в естественно-гуманитарных учебных заведениях.

Идентификация в современном обществе имеет сложную, многоуровневую и динамичную структуру. Это объясняет тот факт, что около 68,4 \% респондентов гордятся фактом своей гражданской идентичности. При этом необходимость целенаправленной «политики идентичности» обусловлена тем, что 13,8 \% ответили, что факт гражданской идентичности «мало что для них значит», 5,9 \% «скептически относятся к этому факту», 0,7 \% «стыдятся того, что являются россиянами», а 11,3 \% затрудняются высказать свое отношение к тому, что являются гражданами РФ. Весьма настораживает тот факт, что четверть студентов не испытывает гордости за собственную гражданскую идентичность, поскольку «строительство гражданской общероссийской идентичности важно для сохранения единства России, чтобы она не раскололась на “этнические квартиры”, а сплотившись, сохранив свое культурное богатство этноразнообразие, заняла достойное место в изменяющемся мире» $[13$, с. 116]. Парадок- сально, что только $85 \%$ респондентов, отожествляющих себя с «гражданами России», испытывают гордость за факт своей гражданской принадлежности. Самый низкий процент гордости за свое гражданство показали студенты федеральных и опорных вузов: ЮФУ (в целом) - 62,3 \%, ДГТУ (в целом) - 64,4\%. Нарушение традиций реализации воспитательных задач при формировании данных крупных образовательных структур, отсутствие преемственности воспитательных методов, склонность к формальным декларациям, характерная для крупных организационных структур, негативно влияют на социализацию студентов этих вузов.

В крупных городах наиболее остро ощущаются несоответствие декларируемой модернизации и реальных возможностей государства, давление вертикальных систем управления, кризис духовности, перформативность современного патриотизма и нехватка площадок для взаимодействия государства и общества $[11$, с. 50]. Этим объясняется диссонанс когнитивного, деятельностного и эмоционального аспектов гражданской идентификации.

Довольно высокий по отношению к другим вузам Ростовской области уровень гордости за свое гражданство показали студенты ДонГАУ (в целом) - 82,3 \%, АЧИИ ДГАУ (г. Зерноград) - 88,2 \% , НИМИ ДГАУ (г. Новочеркасск) - 84,3\%. Среди респондентов из вузов других регионов процент тех, кто гордится собственным гражданством, еще ниже: $42,5 \%$ - УРФУ (г. Екатеринбург); 28,2 \% СКФУ (г. Ставрополь), 41,5 \% - ВолгГТУ (г. Волгоград), 31,2 \% - КФУ (г. Казань), $37,6 \%$ - КалмГУ (г. Элиста), $42 \%$ - АГУ (г. Майкоп). Интерпретация таких показателей, помимо уже обозначенных причин, должна включать и тип высшего учебного заведения. Для респондентов сельскохозяйственных вузов оценка факта собственной гражданской идентичности выше (85,3\%), чем для респондентов из инженерно-технических $(66,4 \%)$ и естественно-гуманитарных $(66,0 \%)$ вузов. Это вполне объяснимо с точки зрения трансляции традиционных российских ценностей при реализации воспитательной политики сельскохозяйственных вузов, склонности к консервативной модели идентичности, типичной для жи- 
телей сельской местности, поддерживаемой спецификой образа жизни селян.

Национальная самоидентификация характерна только для 20,6 \% респондентов и уступает таким ответам, как «назвал бы свою профессию, род занятий» $(30,7 \%)$, «просто сказал бы “человек”» $(38,4$ \%). Несмотря на то что национальная самоидентификация не является лидирующей среди ответов респондентов, можно смело констатировать рост числа респондентов, определяющих себя как члена национальной общности. В целом по вузам Ростовской области этот показатель вырос с 6,0 \% в 2011 г. до 17,4 \% в 2016 году. Положительная динамика национальной самоидентификации вполне объяснима с точки зрения позиций политического и культурологического конструктивизма. При этом следует учитывать, что подъем национального самосознания может идти как по пути роста идентификации членов этнической общности с ней, их сплочения, так и по пути игнорирования интересов других народов, что впоследствии может привести к развитию идеи национальной исключительности. Национальная идентичность должна быть связана с государственной, иначе она приобретает характер источника сепаратизма. С точки зрения Д.О. Кузнецова, «активизация этноконфессиональных идеологий становится вызовом единству и стабильности всего российского общества» $[8$, с. 18$]$.

Именно поэтому при сопоставлении значимости формирования национальной и гражданской идентичности в работе с молодежью, в конструировании целей «политики идентичности» приоритет имеет именно гражданская идентичность. «Основным способом интеграции поликультурного российского социума во все времена был приоритет общегосударственной гражданской идентичности» [8, с. 18].

Формирование позитивной идентичности, обеспечивающей консолидацию и стабильность общества, гармоничное сосуществование личной и социальной идентичности необходимы ввиду того, что идентичность эксплицируется на поведенческом уровне функционирования ментальных конструктов ее носителя.

Так, только 16,7 \% респондентов с гражданской самоидентификацией, 18,8 \% с наци- ональной самоидентификацией, 20,3 \% с региональной и $18,2 \%$ с семейной самоидентификацией допускают для себя уклонение от службы в армии. Респонденты, идентифицирующие себя с европейскими ценностями $(43,3 \%)$, «гражданами мира» $(32,2 \%)$ или затрудняющиеся в определении собственной принадлежности $(24,6$ \%), гораздо чаще допускают для себя уклонение от службы в армии.

Среди респондентов, допускающих для себя уход от оплаты налогов, можно выделить $8,5 \%$ с гражданской самоидентификацией, $8,6 \%$ с региональной, 9,9\% с национальной, 8,4 \% с профессиональной и $6,4 \%$ с семейной. Этот процент значительно выше для респондентов с европейской $(21,8 \%)$, религиозной $(16,1 \%)$, космополитической $(10,9 \%)$ самоидентификацией, тех, кто отождествляет себя с гражданами мира (15,2\%) или испытывает трудности в самоидентификации $(12,3 \%)$.

Подобная закономерность наблюдается и в отношении возможности нарушить закон, если это экономически выгодно: 10,4 \% респондентов, идентифицирующих себя с гражданами России; 17,5 \% - с европейцами; 15,2 \% с гражданами мира; $10,2 \%$ - с жителями региона, села, города; 13,6 \% из тех, кто назвал свою национальность; 14,2 \% из тех, кто назвал свою религиозную принадлежность; 9,7 \% из тех, кто назвал свою профессию, род занятий; 7,5 \% из тех, кто назвал свою семейную роль; 11,8 \% из тех, кто просто отожествляет себя с «человеком»; 16,1 \% из тех, кто затрудняется с ответом, отметили для себя эту возможность.

Анализ поведенческих установок явно показывает особую опасность так называемых «гибридных» моделей идентичности современной молодежи (идентификация себя с «гражданами мира», «европейцами», «просто людьми»).

Личностная и социальная идентификация всегда эмоционально окрашены. Ввиду этого при оценке национальной идентификации весьма интересен анализ социальных аттитюдов. Социальные аттитюды - это психологическое переживание индивидом ценности, значения, смысла социального объекта или состояние сознания относительно некоторой социальной ценности. 
При оценке национальных установок респондентов весьма интересен тот факт, что только 71,7 \% из них гордятся своей национальной принадлежностью, 14,1 \% отмечают, что их национальность мало что для них значит, 6,2 \% не считают, что имеют отношение к какой-либо определенной национальности, 0,5 \% стыдятся своей национальности, а 7,6 \% затрудняются дать оценку своей национальной принадлежности. Следует отметить, что эмоциональная оценка собственной национальной идентичности имеет негативную тенденцию. В 2006 г. около 76,6 \% респондентов отмечали гордость за свою национальную идентичность. В 2011 г. такой показатель составил 75,0 \%, а в 2016 г. - 70,8 \%. Увеличился процент тех, кто отметил факт своей национальной принадлежности как малозначительный (2006 г. - 11,2\%, 2011г. - $13 \%, 2016-13,8 \%$ ), и тех, кто не считает, что может назвать свою национальную идентичность (2006 г. - 5,9 \%, 2011 г. $-6,0 \%, 2016$ г. $-7,9 \%$ ).

Анализ ответов студентов вузов Ростовской области на вопрос «Как Вы определяете свое личное отношение к собственной национальности?» показал, что уровень эмоциональной оценки национальной принадлежности выше у студентов тех вузов, специальности которых тесно связаны с землей, природой, которые располагаются в исторически значимых для казачества районах: Новочеркасске (ЮРГПУ (НПИ) - 79,2 \%), пос. Персиановский (ДонГАУ - 81,5\%), Таганроге (Таганрогский институт имени А.П. Чехова (филиал) РГЭУ - 77,5 \%). Для сравнения только 64,5 \% студентов ЮФУ (в целом), 64,4 \% ДГТУ (в целом) отметили гордость за свою национальную принадлежность.

Респонденты, идентифицирующие себя с «европейцем» $(57,5 \%)$, «гражданином мира» (60,1\%), затрудняющиеся с самоидентификацией $(48,2 \%)$ или просто называющие себя «человек» $(63,7 \%)$, показывают самый низкий уровень оценки собственной национальной принадлежности. Для национальной (90,7\%), гражданской $(83,4 \%)$ или региональной идентичности $(80,5 \%)$ этот показатель значительно выше.

\section{Выводы}

Необходима системная, целенаправленная «политика идентичности», способная скор- ректировать неустойчивые, переходные, негативные формы новых идентичностей современного поколения «Си» [9, с. 213].

Особое внимание в конструировании системы идентификационных координат личности следует уделять гражданской идентичности, которая, несмотря на относительно высокий удельный вес в структуре социальных идентичностей, имеет тенденцию к снижению. При этом зоной риска можно считать молодых людей крупных городов, мегаполисов, студентов вновь созданных федеральных и опорных вузов, имеющих сравнительно небольшую историю.

Скрытый конфликт национальной и гражданской идентичности требует уделять особое внимание вопросу воспроизводства положительной гражданской идентичности в национальных районах России. При конструировании «политики идентичности» необходимо формировать особый взгляд на Россию, единственным и непротиворечивым условием развития которой является сохранение всего уникального спектра народностей.

Необходимо на государственном уровне обеспечить контроль над процессом роста национальной идентичности с целью использования ее в качестве фактора развития национального самосознания, самоидентификации и сплочения членов этнических общностей во избежание возможности игнорирования интересов других народов, а также формирования идеи национальной исключительности.

Поведенческие и эмоциональные аттитюды респондентов с гражданской и национальной идентификацией позволяют выявить высокий уровень гражданской ответственности и склонность к следованию позитивным социальным ожиданиям и нормам.

\section{СПИСОК ЛИТЕРАТУРЫ}

1. Ачкасов, В. А. Политика идентичности в современном мире / В. А. Ачкасов // Вестник СПбГУ. Сер. 6. - 2013. - Вып 4. - С. 71.

2. Гаврилюк, В. В. Современные модели российской гражданственности / В. В. Гаврилюк, В. В. Маленков, Т. В. Гаврилюк // Социологические исследования. - 2016. - № 11. - С. 97-106.

3. Галактионова, Н. А. Гражданская идентичность как компонент личностной идентичности 
/ Н. А. Галактионова // Известия высших учебных заведений. Социология. Экономика. Политика. 2010. - № 1. - C. 10-12.

4. Горшков, М. К. Российский социум в условиях кризисного развития: контекстный подход / М. К. Горшков // Социс. -2016. - № 12. - С. 28-34.

5. Григорьев, Д. В. Формирование гражданской идентичности современного школьника / Д. В. Григорьев // Интернет-конференция «Перспектива гражданско-патриотического воспитания в системе образования». - Электрон. текстовые дан. - Режим доступа: http://proektpatriot2.jimdo. com/гражданская-идентичность (дата обращения: 18.10.2017). - Загл. с экрана.

6. Дробижева, Л. М. Российская идентичность в массовом сознании / Л. М. Дробижева // Вестник российской нации. - 2009. - № 1. - С. 135-146.

7. Иванова, Н. Л. Изменения этнической и гражданской идентичности в новых общественных условиях / Н. Л. Иванова, Г. Б. Мазилова // Вопросы психологии. - 2008. - № 2. - С. 83-93.

8. Кузнецов, Д. О. Факторы гражданской социализации молодежи в современной России : дис. ... канд. социол. наук / Кузнецов Дмитрий Олегович. - Ставрополь, 2016. - С. 18.

9. Мансурова, В. Д. Онлайн социальность поколения «Си»: феноменологии «публичной интимности» / В. Д. Мансурова // Известия Алтайского государственного университета. - 2014. - № 2-1 (82). - C. 213.

10. Пупыкин, Р. А. Специфика интеграции научно-экспертного сообщества (на примере ЮжноРоссийского политологического конвента) / Р. А. Пупыкин // Гуманитарий Юга России. - 2014. - № 4. С. 193-196.

11. Санина, А. Г. Государственная идентичность: издержки виртуализации / А. Г. Санина // Социс. - 2012. - № 3. - С. 77.

12. Санина, А. Г. Государственная идентичность: содержание понятия и постановка проблемы / А. Г. Санина, А. В. Павлов // Управленческое консультирование. - 2015. - № 9. - С. 30-40.

13. Шикова, Р. Ю. Гражданская общероссийская идентичность (социологический аспект) / Р. Ю. Шикова // Вестник Адыгейского государственного университета. Серия 1: Регионоведение. Философия. История. Социология. Юриспруденция. Политология, Культурология. -2009. - № 1. - С. 111-116.

\section{REFERENCES}

1. Achkasov V.A. Politika identichnosti v sovremennom mire [Identity Policy in the Modern World]. Vestnik SPbGU. Ser. 6, 2013, iss. 4, p. 71.

2. Gavrilyuk V.V., Malenkov V.V., Gavrilyuk T.V. Sovremennye modeli rossiyskoy grazhdanstvennosti
[Modern Models of Russian Citizenship]. Sotsiologicheskie issledovaniya, 2016, no. 11, pp. 97-106.

3. Galaktionova N.A. Grazhdanskaya identichnost kak komponent lichnostnoy identichnosti [Civic Identity as a Component of Personal Identity]. Izvestiya vysshikh uchebnykh zavedeniy. Sotsiologiya. Ekonomika. Politika, 2010, no. 1, pp. 10-12.

4. Gorshkov M.K. Rossiyskiy sotsium v usloviyakh krizisnogo razvitiya: kontekstnyy podkhod [Russian Society in Crisis Conditions: Contextual Approach]. Sotsis, 2016, no. 12, pp. 28-34.

5. Grigoryev D.V. Formirovanie grazhdanskoy identichnosti sovremennogo shkolnika [Formation of the Civil Identity of a Modern Pupil]. Internetkonferentsiya "Perspektiva grazhdanskopatrioticheskogo vospitaniya $v$ sisteme obrazovaniya» [Internet conference "Perspective of Civil-Patriotic Education in the Education System"]. URL: http://proektpatriot2.jimdo.com/grazhdanskayaidentichnost'/ (accessed October 18, 2017).

6. Drobizheva L.M. Rossiyskaya identichnost v massovom soznanii [Russian Identity in the Mass Consciousness]. Vestnik rossiyskoy natsii, 2009, no. 1, pp. 135-146.

7. Ivanova N.L., Mazilova G.B. Izmeneniya etnicheskoy i grazhdanskoy identichnosti v novykh obshchestvennykh usloviyakh [Changes in Ethnic and Civic Identity in the New Social Conditions]. Voprosy psikhologii, 2008, no. 2, pp. 83-93.

8. Kuznetsov D.O. Faktory grazhdanskoy sotsializatsii molodezhi v sovremennoy Rossii: dis. ... kand. sotsiol. nauk [Factors of Civil Socialization of Youth in Modern Russia. Cand. social. sci. diss.]. Stavropol, 2016. 18 p.

9. Mansurova V.D. Onlayn sotsialnost pokoleniya «Si»: fenomenologii «publichnoy intimnosti» [Online Sociality of the "C" Generation: the Phenomenology of "Public Intimacy"]. Izvestiya Altayskogo gosudarstvennogo universiteta, 2014, no. 2-1 (82), p. 213.

10. Pupykin R.A. Spetsifika integratsii nauchnoekspertnogo soobshchestva (na primere YuzhnoRossiyskogo politologicheskogo konventa) [Specificity of Integration of the Scientific and Expert Community (on the Example of the South-Russian Political Science Convention)]. Gumanitariy Yuga Rossii, 2014, no. 4, pp. 193-196.

11. Sanina A.G. Gosudarstvennaya identichnost: izderzhki virtualizatsii [State Identity: the Costs of Virtualization]. Sotsis, 2012, no. 3, p. 77.

12. Sanina A.G., Pavlov A.V. Gosudarstvennaya identichnost: soderzhanie ponyatiya i postanovka problemy [State Identity: Content of the Concept and Problem Statement]. Upravlencheskoe konsultirovanie, 2015, no. 9, pp. 30-40. 


\section{СОЦИОЛОГИЯ И СОЦИАЛЬНЫЕ ТЕХНОЛОГИИ}

13. Shikova R.Yu. Grazhdanskaya obshcherossiyskaya identichnost (sotsiologicheskiy aspekt) [Civic All-Russian Identity (Sociological Aspect)]. Vestnik Adygeyskogo gosudarstvennogo universiteta. Seriya 1. Regionovedenie: Filosofiya. Istoriya. Sotsiologiya. Yurisprudentsiya. Politologiya, Kulturologiya, 2009, no. 1, pp. 111-116.

\section{Information about the Authors}

Lyudmila S. Detochenko, Candidate of Philosophical Sciences, Associate Professor, Department of Social Technologies, South Federal University, Bolshaya Sadovaya St., 105/42, 344006 Rostov-onDon, Russian Federation, maksimus6488@yandex.ru.

Viktor I. Filonenko, Doctor of Sociological Sciences, Associate Professor, Professor of Department of Social Technologies, South Federal University, Bolshaya Sadovaya St., 105/42, 344006, Rostov-onDon, Russian Federation, soc-centr-sfedu@yandex.ru.

\section{Информация об авторах}

Людмила Станиславовна Деточенко, кандидат философских наук, доцент кафедры социальных технологий, Южный федеральный университет, ул. Большая Садовая, 105/42, 344006 г. Ростов-на-Дону, Российская Федерация, maksimus6488@yandex.ru.

Виктор Иванович Филоненко, доктор социологических наук, доцент, профессор кафедры социальных технологий, Южный федеральный университет, ул. Большая Садовая, 105/42, 344006 г. Ростов-на-Дону, Российская Федерация, soc-centr-sfedu@yandex.ru. 